\title{
Anxiety Level and Associated Factors during Coronavirus Disease 2019 (COVID-19) Pandemic in Pregnant Women
}

\author{
Leo Simanjuntak* and Patrick Anando Simanjuntak \\ Department of Obstetrics and Gynecology, Faculty of Medicine, Nommensen HKBP \\ University, Medan, Indonesia \\ *Corresponding Author: Leo Simanjuntak, Department of Obstetrics and \\ Gynecology, Faculty of Medicine, Nommensen HKBP University, Medan, Indonesia.
}

Received: April 16, 2020

Published: June 17, 2020

(C) All rights are reserved by Leo

Simanjuntak, et al.

\begin{abstract}
Background: Coronavirus disease-2019 (COVID-19) pandemic is spreading widely throughout the world, causing global health crisis and one of the greatest challenges we have ever faced. Indonesia is one of the countries that has been severely affected by COVID-19. The COVID-19 pandemic has created some serious concerns including anxiety in pregnant women. However, due to mental and physical changes in pregnancy, pregnant women are likely to be affected by the virus. At present there is no evidence that pregnant women are at higher risk of severe illness from COVID-19 than the general population. Research is currently ongoing to understand the impacts of COVID-19 in pregnant women. This study aimed to assess the anxiety level and associated factors during COVID-19 pandemic in pregnant women.

Methods: This study used cross-sectional design using primary data on April 2020 at Leo Simanjuntak(Obstetrician and Gynecologist) outpatient clinic. Based on defined criteria, 120 subjects were recruited in this study. Anxiety level assessed using Hamilton Anxiety Rating Scale (HAM-A). Demographic data collected using research questionnaire. Logistic regression were used to identify associated factors on anxiety level.

Results: Our results showed majority of the pregnant women (71\%) showed no anxiety. The rest of these pregnant women (29\%) showed mild anxiety level (23\%) and moderate anxiety (6\%). Multivariate data analysis showed that healthcare workers were associated to higher anxiety level, with OR 5.56 (95\% CI .33 - 24.09).

Conclusion: Informative and educative advices and suggestions of COVID-19 to pregnant women and their family, such as washing hands frequently, maintain social and physical distancing, using mask to cover the mouth and nose when around others, living healthy life, and doing all the activities from home, can make pregnant women not worried about COVID-19 pandemic, which is supported by this study.

Keywords: Anxiety; Pregnant Women; COVID-19; HAM-A
\end{abstract}

\section{Introduction}

A pneumonia of unknown cause detected in Wuhan, China was first reported to the World Health Organization (WHO) on December 31,2019 . Initially the case was reported in the Wuhan area, Hubei province, China. After three days, there were 44 patients with such cases and today thousands of COVID-19 cases confirmed globally [1]. Coronavirus disease-2019 (COVID-19) pandemic is spreading widely throughout the world, causing global health crisis and one of the greatest challenge we have ever faced. COVID-19 is a cluster of acute respiratory illness caused by the Severe Acute Respiratory Syndrome Coronavirus-2 (SARS-CoV-2) virus.

As of $14^{\text {th }}$ April 2020, a total of 1,844,863 COVID-19 confirmed cases globally spread in 213 countries with a total of $117,021 \mathrm{con}$ - firmed death [2]. While in Indonesia as of April 14, 2020, a total of 4,839 confirmed cases, spread in 34 provinces, with a total of 459 confirmed death [3]. These data show the case fatality rate (CFR) in Indonesia is higher (9.5\%) than the CFR globally (6.3\%).

COVID-19 infection can cause mild, moderate or severe symptoms. The main clinical symptoms are fever $\left(>38^{\circ} \mathrm{C}\right)$, cough and shortness of breath. Moreover, it can be accompanied by fatigue, myalgia, gastrointestinal symptoms such as diarrhea, loss of smell and taste, and other respiratory symptoms. Half of COVID-19 patients will develop shortness of breath in just one week. In severe cases progressively rapid deterioration, such as ARDS (Acute Respiratory Distress Syndrome), septic shock, metabolic acidosis and 
coagulation problem within a few days. Most of the patients have good prognosis, with low morbidity and mortality rate [4].

At present there is no evidence that pregnant women are at higher risk of severe illness from COVID-19 than the general population. However, due to mental and physical changes in pregnancy, pregnant women are likely to be affected by the virus. Research is currently ongoing to understand the impacts of COVID-19 in pregnant women. Emerging evidence suggests that transmission from a woman to the baby during pregnancy or birth (vertical transmission) is probable. Fetal distress and preterm labor are found in some cases $[5,6]$.

On January 30, WHO declared COVID-19 as Public Health Emergency of International Concern, then on March 11, 2020, COVID-19 was declared as pandemic meaning COVID-19 which has spread to several countries or continents and infected many people. Other than causing physical damage, these conditions lead to increased stress and anxiety to the public, including pregnant women. Anxiety is the most common emotional and psychiatric problem in pregnancy. Anxiety in pregnancy can affect pregnancy such as preterm labor, fetal growth restriction, and poor neurobehavioral development [7]. Hamilton Anxiety Rating Scale (HAM-A) is one of the rating scales developed to measure anxiety level and is widely used both in clinical and research settings [8].

\section{Aim of the Study}

The aim of this study is to assess the anxiety level and associated factors during COVID-19 pandemic in pregnant women.

\section{Methods}

This study used cross-sectional design using primary data obtained by analytical survey, on April 2020. The subjects were patients at the Leo Simanjuntak (Obstetrician and Gynecologist) outpatient clinic. Based on defined criteria, 120 participants were recruited in this study, using consecutive sampling. Pregnant women that has been diagnosed with anxiety disorder before and incomplete questionnaire data were excluded from this study.

This study used Indonesian version of Hamilton Anxiety Rating Scale (HAM-A). the Hamilton Anxiety Rating Scale (HAM-A) consists of 14 items, each defined by a series of symptoms, and measures both psychic anxiety (mental agitation and psychological distress) and somatic anxiety (physical complaints related to anxiety). The dimension of HAM-A consists of: (1) anxious mood, (2) tension, (3) fears, (4) insomnia, (5) intellectual, (6) depressed mood, (7) somatic (muscular), (8) somatic (sensory), (9) cardio- vascular symptoms, (10) respiratory symptoms, (11) gastrointestinal symptoms, (12) genitourinary symptoms, (13) autonomic symptoms, and (14) behavior at interview. Each item is scored on a scale of 0 (not present) to 4 (severe), with a total score range of 0 - 56. Participants responded the questionnaire given to the interviewer. This study also used demographic questionnaire to obtain associated factors such as age, occupation, income level, education level, and parity level.

Descriptive analyses were conducted to describe demographic characteristics and the pregnant women anxiety level. Chi-square test was used to compare the differences between groups. multivariate logistic regression models were performed to explore potential associated factors for anxiety level in pregnant women. All data were analyzed using SPSS version 22.0. p-values of less than 0.05 were considered statistically significant.

\section{Results}

The characteristics of subjects were shown in table 1 . Of the 120 subjects, mean age of the subjects was $29.2 \pm 4.7$ years, $92.5 \%$ of subjects were non-healthcare workers, $49 \%$ of subjects had an undergraduate educational background, $50.8 \%$ had middle-class income and $52.5 \%$ of them were nulliparous.

\begin{tabular}{|l|c|}
\hline \multicolumn{1}{|c|}{ Characteristics } & N (\%) \\
\hline Total & $120(100 \%)$ \\
\hline Age (Mean \pm SD) & $29.2 \pm 4.7$ \\
\hline$<35$ years & $20(16.7 \%)$ \\
\hline$\geq 35$ years & \\
\hline Occupation & $9(7.5 \%)$ \\
\hline Healthcare workers & $111(92.5 \%)$ \\
\hline Non-healthcare workers & \\
\hline Educational Background & $1(0.8 \%)$ \\
\hline Primary School & $5(4.2 \%)$ \\
\hline Junior High School & $55(45.8 \%)$ \\
\hline Senior High School & $59(49.2 \%)$ \\
\hline College & \\
\hline Income Level & $17(14.2 \%)$ \\
\hline Low Income & $61(50.8 \%)$ \\
\hline Middle Income & $42(35 \%)$ \\
\hline High Income & \\
\hline Parity Level & $63(52.5 \%)$ \\
\hline Nulliparous & $31(25.8 \%)$ \\
\hline Primiparous & $26(21.7 \%)$ \\
\hline Multiparous & \\
\hline
\end{tabular}

Table 1: Demographic distribution of subjects. 
The prevalence of anxiety level based on age, occupation, education background, income level, and parity level were shown in table 2. The overall prevalence of anxiety was $29 \%$, consists of $23 \%$ of mild anxiety and $6 \%$ of moderate anxiety. There was no statistically significant correlation between age, education background, income level, and parity level, meaning the anxiety level was not affected by these associated factors. But there was statistically significant correlation between occupation and anxiety level. Healthcare workers had higher prevalence of anxiety compared to non-healthcare workers $(\mathrm{p}=0.01)$ as shown in table 2 .
Table 3 shows that occupation may be a potential risk factor to the anxiety level. Healthcare workers had an Odds Ratio of 5.65 (95\% CI 1.33 - 24.09), meaning that healthcare workers have 5.65 times risk to anxiety disorder compared to non-healthcare workers.

\section{Discussion}

This study shows that majority of pregnant women (72\% of participants) had no anxiety during COVID-19 pandemic. Healthcare

\begin{tabular}{|c|c|c|c|c|}
\hline \multirow{2}{*}{ Characteristics } & \multicolumn{3}{|c|}{ Anxiety Level } & \multirow{2}{*}{ p-value } \\
\hline & Not Anxiety & Mild Anxiety & Moderate Anxiety & \\
\hline \multicolumn{4}{|l|}{ Age (Mean \pm SD) } & \multirow[t]{3}{*}{0.098} \\
\hline$<35$ years & $73(73 \%)$ & $20(20 \%)$ & $7(7 \%)$ & \\
\hline$\geq 35$ years & $12(60 \%)$ & $8(40 \%)$ & $0(0 \%)$ & \\
\hline \multicolumn{4}{|l|}{ Occupation } & \multirow[t]{3}{*}{0.01} \\
\hline Healthcare workers & $3(33.4 \%)$ & $4(44.4 \%)$ & $2(22.2 \%)$ & \\
\hline Non-healthcare workers & $82(73.9 \%)$ & $24(21.6 \%)$ & $5(4.5 \%)$ & \\
\hline \multicolumn{4}{|l|}{ Education Background } & \multirow[t]{5}{*}{0.833} \\
\hline Primary School & $1(100 \%)$ & $0(0 \%)$ & $0(0 \%)$ & \\
\hline Junior High School & $3(60 \%)$ & $2(40 \%)$ & $0(0 \%)$ & \\
\hline Senior High School & $41(74.5 \%)$ & $10(18.2 \%)$ & $4(7.3 \%)$ & \\
\hline Undergraduate & $40(67.8 \%)$ & $16(27.1 \%)$ & $3(5.1 \%)$ & \\
\hline \multicolumn{4}{|l|}{ Income Level } & \multirow[t]{4}{*}{0.964} \\
\hline Low Income & $13(76.5 \%)$ & $3(17.6 \%)$ & $1(5.9 \%)$ & \\
\hline Middle Income & $43(70.5 \%)$ & $15(24.6 \%)$ & $3(4.9 \%)$ & \\
\hline High Income & $29(69 \%)$ & $10(23.8 \%)$ & $3(7.1 \%)$ & \\
\hline \multicolumn{4}{|l|}{ Parity Level } & \multirow[t]{4}{*}{0.325} \\
\hline Nulliparous & $47(74.6 \%)$ & $14(22.2 \%)$ & $2(3.2 \%)$ & \\
\hline Primiparous & $23(74.2 \%)$ & $5(16.1 \%)$ & $3(9.7 \%)$ & \\
\hline Multiparous & $15(57.7 \%)$ & $9(34.6 \%)$ & $2(7.7 \%)$ & \\
\hline
\end{tabular}

Table 2: Anxiety level based on associated factors.

\begin{tabular}{|c|c|c|c|c|}
\hline \multirow{2}{*}{ Occupation } & \multicolumn{2}{|c|}{ Anxiety Level } & \multirow{2}{*}{ p-value } & \multirow{2}{*}{ OR (95\% CI) } \\
\cline { 2 - 3 } & Anxiety & Not Anxiety & & \multirow{2}{*}{0.01} \\
\hline Healthcare workers & $6(66.7 \%)$ & $3(33.3 \%)$ & 5.65 \\
Non-healthcare workers & $29(26.1 \%)$ & $82(73.9 \%)$ & & $(1.33-24.09)$ \\
\hline
\end{tabular}

Table 3: Prevalence and odds ratio of anxiety based on occupation.

workers had higher prevalence of anxiety compared to non-healthcare. Anxiety level was independent of or was not affected by age, education background, income level, and parity level. Based on 14 components of HAM-A, two of the most severe items are about anxious mood and fears.

In bivariate analysis, we found that occupation may be a potential risk factor to the anxiety level. Healthcare workers had an
Odds Ratio of 5.65 (95\% CI 1.33 - 24.09), meaning that healthcare workers have 5.65 times risk to anxiety disorder compared to nonhealthcare workers. This result was similar to previous study in China during COVID-19 pandemic, showing that healthcare workers had 1.30 Odds Ratio (95\% CI 0.83 - 2.04) compared to other occupations [9]. The possible reason for this is during an outbreak, healthcare workers are expected to work overtime under signifi- 
cant pressure with often inadequate resources including limited personal protective equipment (PPE), while keep in close contact with confirmed or suspect patients. Healthcare workers like everyone else, are vulnerable to the disease itself, hence increase their anxiety levels. The other main concern among healthcare workers is the danger of contracting the disease, especially in Indonesia. As of April 7, 2020, 31 Indonesian healthcare workers died of COVID-19 while hundreds others had tested positive for COVID-19 [10].

These results show pregnant women's anxiety level is relatively low, which was a good news, despite public's levels of anxiety related symptoms increase. Based on in-depth interview, majority of the participants stated the common reasons, including the belief that maintaining a healthy lifestyle, washing hands frequently, maintaining social and physical distancing, using mask to cover the mouth and nose when around others, doing all the activities from home (including doing work and prayer), and timing to seek for medical help as early as possible if there's an emergency can protect themselves against COVID-19. Most of the pregnant women get the informative and educative suggestions about COVID-19 mostly from mass media such as news on television and online newspaper.

The Indonesian Government has prepared many strategies and policies in short time to curb the spread of COVID-19 pandemic and to help the affected public sector. The government issued the regulation on large-scale social distancing to restrict the movement of people and goods. The other policies are large-scale social restrictions, including closure of mass-gathering places like school and workplaces, restrictions on religious activities, restrictions on activities in public places, requiring healthy people to isolate themselves at home, asking everyone to wear masks into public places, and a temporary ban on foreigners entering Indonesia. To help the public sector and avoid people losing their incomes due to mass unemployment, the government has issued regulations about state financial and financial stability. The regulations consist of setting up funds mainly to meet the PPE, rapid test kits, ventilators requirements, exemption on electricity costs, giving incentives, and to provide the food supplies. These regulations and policies by Indonesian government is also playing an important role to ensure the people, including pregnant women they're well taken care of and reduce the anxiety level during COVID-19 pandemic.

\section{Conclusion}

This study identifies that occupational status on pregnant women may be a potential risk factor to the anxiety level during COVID-19 pandemic. Informative and educative advices and suggestions of COVID-19 to pregnant women and their family, such as maintaining a healthy lifestyle, washing hands frequently, maintaining social and physical distancing, using mask to cover the mouth and nose when around others, doing all the activities from home (including doing work and prayer), and timing to seek for medical help as early as possible if there's an emergency can protect themselves against COVID-19 and not worried about COVID-19 pandemic, which is supported by this study.

\section{Bibliography}

1. WHO. "Novel Coronavirus (2019-nCoV) Situation Report-1" (2020).

2. WHO. "Coronavirus disease 2019 (COVID-19) Situation Report-84" (2020).

3. BNPB. Situasi Virus Corona (2020).

4. Wang Z., et al. "A Handbook of 2019-nCoV Pneumonia Control and Prevention". Hubei Science and Technology Press, China (2020).

5. Fan C., et al. "Perinatal Transmission of COVID-19 Associated SARS-CoV-2: Should We Worry?” Clinical Infectious Disease (2020).

6. ACOG Practice Advisory: Novel Coronavirus 2019 (COVID-19). The American College of Obstetricians and Gynecologists (2020).

7. Leveno KJ., et al. "Williams Obstetrics". $25^{\text {th }}$ edition. Cunningham FG, editor. New York: McGraw-Hill Education (2018).

8. Thompson E. "Hamilton rating scale for anxiety (HAM-A)". Occupational Medicine 65.7 (2015): 601.

9. Zhao N and Huang Y. "Generalized anxiety disorder, depressive symptoms and sleep quality during COVID-19 epidemic in China: a web-based cross-sectional survey". Psychiatry Research 288 (2020): 112954.

10. Schwartz J., et al. "Protecting Healthcare Workers During the Coronavirus Disease 2019 (COVID-19) Outbreak: Lessons from Taiwan's Severe Acute Respiratory Syndrome Response". Clinical Infectious Diseases (2020).

\section{Assets from publication with us}

- Prompt Acknowledgement after receiving the article

- Thorough Double blinded peer review

- Rapid Publication

- Issue of Publication Certificate

- High visibility of your Published work

Website: www.actascientific.com/

Submit Article: www.actascientific.com/submission.php Email us: editor@actascientific.com

Contact us: +919182824667 